\title{
Polimerização convencional e por ebulição: efeito nas propriedades brilho, rugosidade, dureza e resistência ao impacto de resinas acrílicas
}

\author{
Bianca L Folli (IC), Rafael L X Consani (PQ), Moises C F Nogueira (PG).
}

\section{Resumo}

O objetivo neste estudo foi avaliar o efeito da polimerização convencional e por ebulição nas propriedades brilho, rugosidade, dureza e resistência ao impacto de resinas acrílicas. As propriedades brilho, rugosidade, dureza e resistência ao impacto de resinas acrílicas não foram influenciadas pelas técnicas de polimerização.

Palavras Chave: Resina acrílica, propriedades físicas, polimerização.

\section{Introdução}

A rugosidade de superfície de base de prótese está intimamente relacionada com o acúmulo de biofilme e pigmentação extrínseca, enquanto a dureza se relaciona com a abrasividade e desgaste dos materiais poliméricos ${ }^{1}$. O brilho do material é uma característica extremamente importante que tem efeito sobre a percepção da cor e está diretamente relacionado com as condições de polimento da superfície da base de prótese ${ }^{2}$. Propriedades mecânicas, tais como dureza e resistência ao impacto desempenham funções importantes no uso de resinas acrílicas, considerando que alterações ao longo do uso podem promover amolecimento da superfície das resinas influenciando no desgaste e na rugosidade podendo favorecer o acúmulo de biofilme.

Outro fato que pode alterar a condição de lisura da superfície de resinas é a ocorrência de microporosidades, do estágio plástico, da temperatura de polimerização, da pressão insuficiente durante a polimerização e da viscosidade das resinas ${ }^{3}$.

Além disso, fatores inerentes às propriedades físicas da resina, diferentes processamentos ${ }^{4,5} \mathrm{e}$ relação significante entre dureza, rugosidade e brilho, e da resistência ao impacto, seria conveniente verificar o efeito de tipos de polimerização sobre essas variáveis.

\section{Resultados e Discussão}

Os resultados submetidos à ANOVA e teste de Tukey $(5 \%)$ mostraram que não houve diferença significante entre grupos, embora a resina polimerizada convencionalmente tivesse melhor desempenho nas propriedades avaliadas em comparação com a polimerizada por ebulição. Não houve diferença significante entre métodos de polimerização e entre resinas. Esses resultados não concordam com estudos anteriores, quando alteração dimensional linear, dureza e resistência ao impacto de resinas seriam influenciadas pelos ciclos de polimerização ${ }^{6}$, assim como desinfecção simulada por microondas $^{7}$. Diferenças de dureza entre resinas ativadas convencionalmente, por ebulição e micro-ondas existem nessas resinas ${ }^{8}$. No estudo, as diferenças não ocorreram porque as resinas têm similar composição básica. Alega-se também que valores similares de resistência à fratura são devidos à resiliência ${ }^{8}$, fato verificado no estudo.

Brilho e rugosidade são material-dependente e influenciadas pelo polimento e força; ou seja, rugosidade e brilho variam entre materiais. $O$ brilho é mais consistente do que a rugosidade, apesar da estreita associação ${ }^{9}$. Como polimento e força foram padronizadas, os resultados foram similares. Como lisura e brilho são dependentes da dureza ${ }^{7}$, os resultados seguiram este padrão.

\section{Conclusões}

As propriedades brilho, rugosidade, dureza e resistência ao impacto de resinas acrílicas não foram influenciadas pelas técnicas de polimerização.

\section{Agradecimentos}

\section{Ao SAE/PIBIC/UNICAMP.}

\footnotetext{
${ }^{1}$ Jung M, Eichelberger K, Klimek J. Oper Dent 2007; 32: 347-55.

${ }^{2}$ Kakaboura A, Fragouli M, Rahiotis C, Silikas N. J Mater Sci Mater Med 2007; 18: 155-63.

${ }^{3}$ Anusavice KJ. Phillips Materiais Dentários. Elsevier: 2005.

${ }^{4}$ Jackson AD, Grisius RJ, Fenster RK, Lang BR. Int J Prosthodont 1989; 2 : 421-8

${ }^{5}$ Takamata T, Setcos JC, Phillips RW, Boone ME. J Am Dent Assoc 1989; 119: 271-6.

${ }^{6}$ Consani RLX, Vieira ML, Mesquita MF, Sinhoreti MAC, Guiraldo RD, Nóbilo MAA. Minerva Stomatol 2012; 61: 272-81.

Consani RLX, Pucciarelli MGR, Mesquita MF, Nogueira MCF, Barao VAR. Int J Cont Dent and Med Res 2014; 2014: 1-6.

${ }^{8}$ Consani RLX, Vieira EB, Mesquita MF, Mendes WB, Arioli-Filho JN. Braz Dent J 2008; 19: 348-53.

${ }^{9}$ Heintze SD, Forjanic M, Rousson V. Dent Mater 2006; 22:146-65.
} 